\title{
The importance to including objective functional outcomes in the clinical follow up of total knee arthroplasty patients.
}

Citation for published version (APA):

Senden, R. H. J., Grimm, B., Meijer, K., Savelberg, H. H. C. M., \& Heyligers, I. C. (2011). The importance to including objective functional outcomes in the clinical follow up of total knee arthroplasty patients. Knee, 18(5), 306-311. https://doi.org/10.1016/j.knee.2010.07.008

Document status and date:

Published: 01/10/2011

DOI:

10.1016/j.knee.2010.07.008

Document Version:

Publisher's PDF, also known as Version of record

Document license:

Taverne

Please check the document version of this publication:

- A submitted manuscript is the version of the article upon submission and before peer-review. There can be important differences between the submitted version and the official published version of record.

People interested in the research are advised to contact the author for the final version of the publication, or visit the DOI to the publisher's website.

- The final author version and the galley proof are versions of the publication after peer review.

- The final published version features the final layout of the paper including the volume, issue and page numbers.

Link to publication

\footnotetext{
General rights rights.

- You may freely distribute the URL identifying the publication in the public portal. please follow below link for the End User Agreement:

www.umlib.nl/taverne-license

Take down policy

If you believe that this document breaches copyright please contact us at:

repository@maastrichtuniversity.nl

providing details and we will investigate your claim.
}

Copyright and moral rights for the publications made accessible in the public portal are retained by the authors and/or other copyright owners and it is a condition of accessing publications that users recognise and abide by the legal requirements associated with these

- Users may download and print one copy of any publication from the public portal for the purpose of private study or research.

- You may not further distribute the material or use it for any profit-making activity or commercial gain

If the publication is distributed under the terms of Article 25fa of the Dutch Copyright Act, indicated by the "Taverne" license above, 


\title{
The importance to including objective functional outcomes in the clinical follow up of total knee arthroplasty patients
}

\author{
Rachel Senden ${ }^{\mathrm{a}, \mathrm{b}, *}$, Bernd Grimm ${ }^{\mathrm{a}}$, Kenneth Meijer ${ }^{\mathrm{b}}$, Hans Savelberg ${ }^{\mathrm{b}}$, Ide C. Heyligers ${ }^{\mathrm{a}, \mathrm{b}}$ \\ a Atrium Medical Centre, Department Orthopedics E Traumatology, Henri Dunantstraat 5, 6419 PC Heerlen, The Netherlands

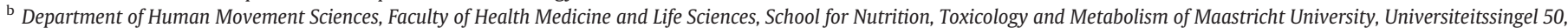 \\ 6229 ER Maastricht, P.O. Box 616, 6200 MD Maastricht, The Netherlands
}

\section{A R T I C L E I N F O}

\section{Article history:}

Received 6 April 2010

Received in revised form 20 July 2010

Accepted 20 July 2010

\section{Keywords:}

Acceleration-based gait analysis

Functional outcome

Follow up

\begin{abstract}
A B S T R A C T
In clinical practice, it is increasingly important to assess patients' daily functionality routinely and objectively. Acceleration-based gait analysis (AGA) has shown to be reliable and technically suitable for routine clinical use outside the laboratory. This study investigated the suitability of AGA for measuring function in orthopaedic patients with symptomatic gonarthrosis listed for total knee arthroplasty (TKA) by investigating (a) the ability of AGA to distinguish patients from healthy subjects, (b) the sensitivity to gait changes of AGA in assessing recovery following total knee arthroplasty in a subpopulation, and (c) correlations between AGA parameters and clinical scales. Gait was assessed using AGA in 24 patients with symptomatic gonarthrosis listed for TKA, and in 24 healthy subjects. AGA parameters (e.g. speed, asymmetry) and clinical scales (e.g. KSS) were used to monitor progress in 12 patients 3 months after TKA. The Mann-Whitney- $U$ test, Receiver Operating Characteristic (ROC) curves, repeated measurement ANOVA and Pearson correlations were performed. AGA differentiated pathological from healthy gait. The area under the ROC curve, sensitivity and specificity values were high for speed, step frequency and step length. Different recovery profiles were found, with clinical scales showing faster recovery rates. None or only weak correlations were found between AGA and clinical scores. AGA was found to be of clinical relevance in identifying and monitoring patients with symptomatic gonarthrosis in orthopaedic practice, providing objective and additional information about function beyond clinical scales. This, together with the fact that AGA can be applied routinely, suggests the suitability of AGA for use in rehabilitation programs.
\end{abstract}

(c) 2010 Elsevier B.V. All rights reserved.

\section{Introduction}

Pain relief and the improvement of knee function are the two main reasons for total knee arthroplasty (TKA) [1,2]. It has recently been shown that for the new generation of TKA patients, who are younger and much more demanding, function becomes increasingly important [3]. Patients expect optimal functional levels after surgery. This makes it important to supervise the recovery process carefully and monitor the outcome of surgery, and to assess functionality in daily life frequently.

Clinical outcome scales, such as, for example, the Western Ontario and McMaster University Osteoarthritis Index (Womac) and the Knee Society Score (KSS), are popular in clinical practice for function assessment because they are non-invasive and easy to use [4]. The perceived mobility status during daily activities is assessed by questionnaire, resulting in clinical outcome scales that are pain-

\footnotetext{
* Corresponding author. Atrium Medical Centre, Department Orthopedics \& Traumatology, Henri Dunantstraat 5, 6419 PC Heerlen, The Netherlands. Tel.: + 31 43881383; fax: + 31433670972.

E-mail address: rachel.senden@bw.unimaas.nl (R. Senden).
}

dominated and subjective. This may mask the actual functioning of an individual; laboratory-based motion analysis systems found differences in function between surgical intervention groups whereas no difference was found using clinical outcome scales [2,4,5]. Although there is some dispute, studies have shown that clinical outcome scales are valid, reliable and responsive [4,6-8]. Maximal performance tests, such as the Timed Up and Go Test, have been shown to be a valid addition to the portfolio of clinical outcome scales, since each assessment method covers a different dimension of function; function is assessed objectively as well as subjectively. However, the outcomes of these maximal performance tests (e.g. time taken to perform a task, distance walked in 6 minutes) have been shown to be too simplistic as they provide no information about the quality of performance. In addition, maximal performance tests are more of a fitness test (e.g. perform this task as fast/well as you can) rather than being related to activities of daily life $[5,9]$.

Because walking is one of the basic activities of daily life, gait analysis is frequently used as a measure of function in daily living. To overcome the subjectivity and pain-dominance of clinical outcome scales gait analysis has been recommended as an additional means of evaluating patients [10]. Currently, in clinical practice analysis of gait 
is done mainly by visual observation because this is the easiest and fastest method of assessment $[2,11]$. However, this method has been shown to be inadequate for accurate assessment of gait [12]. Laboratory-based motion analysis systems, such as 3D-motion analysis, provide accurate gait analysis, and have been used to evaluate the success of surgical intervention and to monitor the progress of pathologies $[2,13]$. However, the complexity, high costs and practical set-up requirements of these techniques (labdependency, wired equipment, small and short walkway) make them less suitable for routine clinical use. As an alternative, a portable and easy-and-quick-to-use acceleration-based gait analysis (AGA) test has become available. Recently, the AGA-test has proved reliable and reproducible in assessing gait in healthy subjects in normal hospital settings [14]. It has also been shown to be sensitive enough to detect small changes in gait evoked by simulated functional knee limitations in healthy subjects while performing a walking test [15]. These characteristics of AGA make it suitable for routine clinical use, allowing the objective assessment of function in many subjects in a relatively short time period, outside standard laboratory settings, the latter providing conditions more closely resembling daily life. Moreover, using AGA assessments the function of patients can be monitored frequently and objectively during recovery, providing more detailed insight into their functional progress and remaining impairments. Deviations from normal walking patterns can be identified early allowing therapy adjustments which may ultimately improve rehabilitation.

The current study investigated the suitability of AGA for monitoring function in orthopaedic patients with symptomatic gonarthrosis listed for TKA. First, the ability of AGA to distinguish patients from matched healthy subjects was investigated. Second, the sensitivity of AGA to gait changes was investigated by studying the recovery of gait in patients following total knee implantation. Third, correlations between AGA parameters and clinical outcome scales were calculated to investigate whether AGA provides additional information about function beyond the clinical scales.

\section{Materials and methods}

\subsection{Patients}

In a case-control study, a cohort of 24 patients $(11 \mathrm{M} / 13 \mathrm{~F}$, mean age $70 \pm 8$ years, weight $85 \pm 15 \mathrm{~kg}$, height $1.69 \pm 0.09 \mathrm{~m}$, BMI $30.0 \pm$ $8.0 \mathrm{~kg} / \mathrm{m}^{2}$ ) suffering symptomatic gonarthrosis of the knee and receiving unilateral TKA, and 24 age-, gender-, height- and weightmatched healthy subjects $(11 \mathrm{M} / 13 \mathrm{~F}$, mean age $70 \pm 8$ years, weight $79 \pm 16 \mathrm{~kg}$, height $1.71 \pm 0.09 \mathrm{~m}$, BMI $27.29 \pm 4.0 \mathrm{~kg} / \mathrm{m}^{2}$ ) were included to investigate whether AGA can differentiate pre-operative TKA patients from healthy controls. All patients received the Uncemented Scorpio total knee system (Stryker) using a parapatellar or subvastus approach. The operation was performed by two experienced surgeons. After-treatment was similar for all patients following the same rehabilitation protocol. Full weight-bearing and active exercises were commenced the first day after surgery. The average hospital stay was 4.5 days.

In a prospective cohort study including a subpopulation of the patient group as convenience sample, 12 patients $(6 \mathrm{M} / 6 \mathrm{~F}$, mean age $67 \pm 10$ years, height $1.71 \pm 0.08 \mathrm{~m}$, weight $84 \pm 15 \mathrm{~kg}, 29 \pm 6 \mathrm{~kg} / \mathrm{m}^{2}$ ) were followed for 3 months, including surgical intervention. Measurements were taken pre-operatively, 2 weeks, 6 weeks and finally 3 months following surgery. An age-, gender-, height- and weightmatched subpopulation of the healthy control group $(6 \mathrm{M} / 6 \mathrm{~F}$, mean age $67 \pm 9$ years, height $1.72 \pm 0.08 \mathrm{~m}$, weight $84 \pm 16 \mathrm{~kg}$, BMI $28 \pm$ $4 \mathrm{~kg} / \mathrm{m}^{2}$ ) was included as a control group serving as reference with which to compare the 3 months post-operative values. The study was approved by the local ethical committee; all participants gave their informed consent.

\subsection{Clinical outcome scales}

Clinical outcome scales, the Knee Society Score (knee and function score), the Womac (pain, function and stiffness score), the Pain Disability Index (PDI) and the Visual Analogue Score used as a pain scale (VAS) were measured pre-operatively, at 2 weeks, 6 weeks and 3 months post-operative in the patient group. These scales were not applied to the control group, as healthy subjects are assumed to score maximum on these clinical outcome scales [7].

\subsection{Acceleration-based gait analysis (AGA)}

Gait was analyzed using a triaxial accelerometer (Minimod, McRobertsBV; dimensions $62 \times 41 \times 18 \mathrm{~mm}, 53 \mathrm{~g}, f=100 \mathrm{~Hz}$ [16]) which was fixed to the skin at the level of the sacrum using adhesive tape (Fig. 1). Subjects walked a $20 \mathrm{~m}$ straight distance in a hospital corridor six times at their preferred speed. All subjects walked without the use of walking aids. Gait parameters were calculated by proprietary, non-disclosed algorithms of the manufacturer based on the algorithms by Zijlstra and Brandes et al. [17]. The basic gait parameters evaluated were step length, step frequency and walking speed. Other clinically relevant parameters included were vertical displacement of the Centre of Mass (CoM), and gait irregularity, which indicates the variability in successive steps of the same leg. The irregularity was calculated as the average of the standard deviation of the left step time and the standard deviation of the right step time. The left-right asymmetry was calculated afterwards as the difference between the average left and right step time divided by the bilateral average (left and right step times determined by the proprietary, nondisclosed algorithms of the manufacturer). Averages of the gait parameters over the six trials were used for analysis. To minimize the inter-subject variation in gait between the patients and the healthy group, the step length, step frequency, speed and vertical displacement of the body were scaled for leg length (based on body height) according to Hof [18].

\subsection{Statistical analysis}

After testing the data for normality, the ability of AGA to distinguish patients with symptomatic gonarthrosis listed for TKA from matched healthy subjects was evaluated by comparing AGA parameters between both groups with the independent $t$-test or the MannWhitney U-test. Receiver operating characteristic (ROC) curves were calculated. The area under the curve (AUC) of the ROC, and sensitivity and specificity values were determined to set threshold values distinguishing pre-operative TKA patients from healthy subjects. The closer values of AUC are to $100 \%$, the better the discriminative power between healthy and pathological gait. Optimal thresholds for gait parameters were determined based on the best balance of sensitivity and specificity. Changes over time in AGA parameters and clinical outcome scales were evaluated by repeated measurement ANOVA using LSD for multiple comparisons. The independent $t$-test or the Mann-Whitney $U$-test was used to compare gait of 3 month postoperative patients with the healthy control group. Pearson correlations were used to test the correlations between clinical outcome scales and AGA parameters. All statistical operations were performed using SPSS version 15.0 and differences were considered significant if $p$-values were less than 0.05 .

\section{Results \\ 3.1. AGA parameters: discriminating patients from healthy participants}

Patients indicated for TKA differed significantly in gait from healthy subjects. Preoperative TKA patients walked significantly more slowly $(1.02 \pm 0.19 \mathrm{~m} / \mathrm{s}$ vs. $1.33 \pm$ $0.16 \mathrm{~m} / \mathrm{s}, p<0.00)$, with smaller steps $(0.60 \pm 0.08 \mathrm{~m}$ vs. $0.69 \pm 0.08 \mathrm{~m}, p<0.00)$, lower step frequency $(1.69 \pm 0.18 \mathrm{steps} / \mathrm{s}$ vs.1.92 $\pm 0.17 \mathrm{steps} / \mathrm{s}, p<0.00)$, higher vertical 

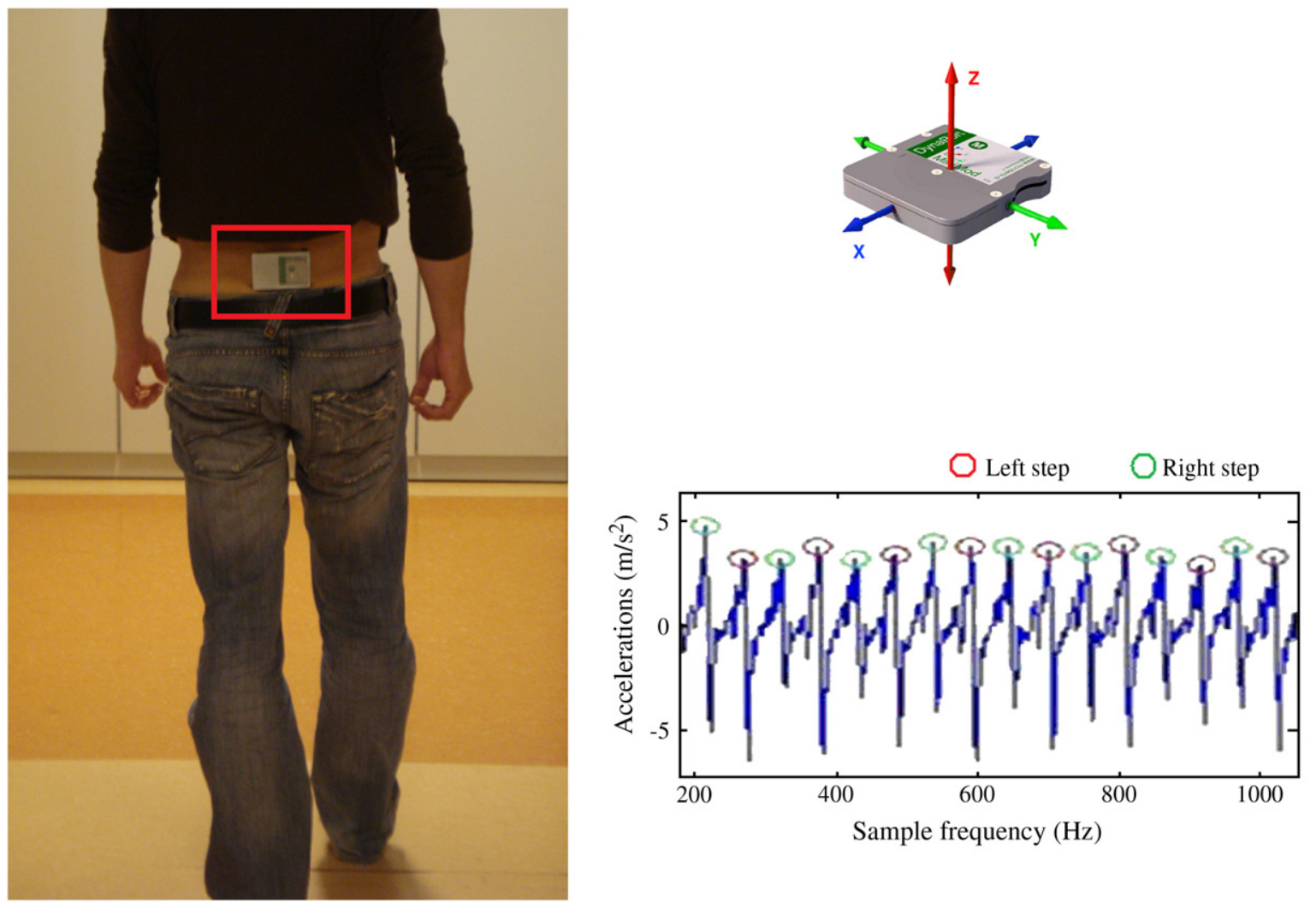

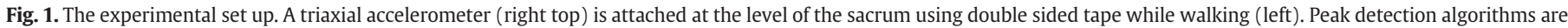
used to recognize steps from the anterior-posterior acceleration signal (right bottom).

displacements $(4.89 \pm 1.43 \mathrm{~cm}$ vs. $4.13 \pm 8.78 \mathrm{~cm}, p=0.03)$, higher irregularity $(2.9 \pm$ $1.4 \%$ vs. $2.3 \pm 1.9 \%, p=0.03$ ) and higher asymmetry ( $5.8 \pm 4.6 \%$ vs. $3.4 \pm 3.2 \%, p=0.05)$. Leg length corrected gait parameters showed similar differences (Table 1). Based on the ROC curves, the following gait parameters showed good discriminative power in delineating pathological from healthy performance; walking speed, step frequency and step length (range AUC 83-89\%). Walking speed, step frequency and step length showed high sensitivity (range 83-96\%) and specificity (range 67-71\%). Lower AUC (range 15-35\%) results were found for vertical displacement, asymmetry, irregularity and step time (Table 2). Similar results were found for the height-corrected gait parameters.

\subsection{Post-surgery recovery patterns}

In the first weeks after TKA, AGA parameters showed impaired function compared to healthy, and even pre-op, status. At 2 weeks following surgery, significant reductions of $22 \%$ in step frequency, $31 \%$ in walking speed and $13 \%$ in step length compared to baseline were recorded. Two weeks after surgery, vertical displacement, step time and asymmetry showed increases of $101 \%, 29 \%$ and $91 \%$ respectively compared to the preoperative assessment (Table 3 ). In contrast, the VAS, KSS (function and knee score) and

Table 1

Comparison of the leg length corrected gait parameters between pre- and 3 months post-operative patients and age-matched healthy subjects.

\begin{tabular}{|c|c|c|c|c|c|}
\hline & & \multicolumn{4}{|c|}{ Leg length corrected parameters } \\
\hline & & Step frequency & Speed & Step length & Vert. displ. \\
\hline \multirow[t]{3}{*}{ n $24 / 24$} & Pre op & $0.50 \pm 0.05$ & $0.36 \pm 0.07$ & $0.71 \pm 0.08$ & $0.06 \pm 0.02$ \\
\hline & $\begin{array}{l}\text { Matched } \\
\text { healthy }\end{array}$ & $0.57 \pm 0.04$ & $0.46 \pm 0.06$ & $0.81 \pm 0.07$ & $0.05 \pm 0.01$ \\
\hline & $p$-value & $0.00^{*}$ & $0.00^{*}$ & $0.00^{*}$ & $0.04^{*}$ \\
\hline \multirow[t]{3}{*}{ n $12 / 12$} & $3 \mathrm{~m}$ post-op & $0.52 \pm 0.03$ & $0.40 \pm 0.05$ & $0.76 \pm 0.08$ & $0.053 \pm 0.01$ \\
\hline & $\begin{array}{l}\text { Matched } \\
\text { healthy }\end{array}$ & $0.57 \pm 0.04$ & $0.47 \pm 0.05$ & $0.84 \pm 0.07$ & $0.051 \pm 0.01$ \\
\hline & $p$-value & $0.01^{*}$ & $0.00^{*}$ & $0.03^{*}$ & 0.41 \\
\hline
\end{tabular}

Averages $\pm \mathrm{SD},{ }^{*} p<0.05$; Vert. displ.: vertical displacement of CoM.
PDI scores were similar 2 weeks after surgery compared to pre-operative. With Womac (total score, pain and function subscore), the score was significantly better (range 33$39 \%$ ) at 2 weeks post-operative compared to pre-operative. Six weeks following surgery, AGA parameters (except asymmetry) and clinical outcome scales (except PDI) were significantly improved compared to the 2 weeks post-operative assessment, showing improvements ranging between $17 \%$ and $48 \%$ for gait parameters and between $23 \%$ and $49 \%$ for clinical outcome scales. At 6 weeks following surgery, gait parameters just reached pre-operative levels, whereas KSS (knee and function), Womac (pain, function, total) and PDI significantly exceeded pre-operative levels. Clinical outcome scales continued to improve between the 6 weeks and 3 month post-operative assessments, showing significantly better scores 3 months post-operative compared to pre-operative. AGA parameters only started to improve from 6 weeks postoperatively, but no significant improvement compared to pre-operative was found 3 months following surgery. In addition, the functional status at 3 months postoperative as measured by AGA was still well below healthy levels (Table 1). Three months post-operative patients still walked significantly more slowly $(1.14 \pm 0.16 \mathrm{~m} / \mathrm{s}$ vs. $1.38 \pm 0.13 \mathrm{~m} / \mathrm{s}, p<0.00)$, with significantly lower step frequency $(1.77 \pm 0.12 \mathrm{steps} / \mathrm{s}$ vs. $1.92 \pm 0.17$ steps $/ \mathrm{s}, p=0.02)$, smaller step length $(0.65 \pm 0.08 \mathrm{~m}$ vs. $0.72 \pm 0.07 \mathrm{~m}$, $p=0.02)$, significantly higher step times $(0.57 \pm 0.04 \mathrm{~s}$ vs. $0.53 \pm 0.04 \mathrm{~s}, p=0.02)$ and asymmetry $(6.5 \pm 4.5 \%$ vs. $2.3 \pm 2.0 \%, p=0.01)$ compared to the healthy age-matched group. The irregularity $(2.2 \pm 0.9 \%$ vs. $2.1 \pm 1.7 \%, p=0.38)$ and vertical displacement $(4.44 \pm 1.11 \mathrm{~cm}$ vs. $4.27+0.84 \mathrm{~cm}, p=0.068)$ were slightly higher in the patient group;

Table 2

The area under the curve (AUC) of the ROC, sensitivity and specificity values with their corresponding threshold values distinguishing pre operative TKA patients from healthy subjects.

\begin{tabular}{lllll}
\hline & AUC (\%) & Sensitivity (\%) & Specificity (\%) & Threshold \\
\hline Speed (m/s) & 89 & 96 & 71 & 1.11 \\
Step frequency (steps/sec) & 84 & 88 & 67 & 1.74 \\
Step length (m) & 83 & 83 & 71 & 0.60 \\
Step time (s) & 15 & 54 & 13 & 0.53 \\
Vertical displacement (m) & 34 & 58 & 29 & 3.90 \\
Asymmetry (\%) & 35 & 58 & 25 & 2.02 \\
Irregularity (\%) & 32 & 54 & 42 & 1.95 \\
\hline
\end{tabular}


Table 3

Averages \pm SD for clinical outcome scales and gait parameters at different follow up times.

\begin{tabular}{|c|c|c|c|c|c|c|c|}
\hline \multirow[b]{2}{*}{$n=12$} & \multicolumn{7}{|c|}{ Follow up time } \\
\hline & Pre & 2 weeks & $p$-value & 6 weeks & $p$-value & 3 months & $p$-value \\
\hline VAS & $3.4 \pm 2.7$ & $3.9 \pm 2.5$ & 0.65 & $2.0 \pm 1.7$ & 0.14 & $1.9 \pm 2.3$ & 0.13 \\
\hline KSS knee & $56.8 \pm 15.4$ & $57.5 \pm 15.2$ & 0.89 & $73.8 \pm 17.7$ & $0.02^{*}$ & $81.3 \pm 15.6$ & $0.00^{*}$ \\
\hline KSS function & $45.8 \pm 14.4$ & $49.9 \pm 9.5$ & 0.49 & $71.0 \pm 13.1$ & $0.01^{*}$ & $82.9 \pm 11.3$ & $0.00^{*}$ \\
\hline Womac pain & $12.8 \pm 5.2$ & $8.6 \pm 3.5$ & $0.00^{*}$ & $5.9 \pm 3.7$ & $0.01^{*}$ & $5.6 \pm 4.2$ & $0.00^{*}$ \\
\hline Womac stiffness & $5.2 \pm 1.6$ & $4.8 \pm 1.5$ & 0.45 & $3.7 \pm 2.4$ & 0.10 & $3.6 \pm 2.0$ & 0.06 \\
\hline Womac function & $42.1 \pm 16.8$ & $25.7 \pm 8.0$ & $0.01^{*}$ & $18.8 \pm 8.7$ & $0.00^{*}$ & $18.6 \pm 11.7$ & $0.00^{*}$ \\
\hline Womac total & $60.1 \pm 22.7$ & $39.0 \pm 11.7$ & $0.01^{*}$ & $28.4 \pm 13.3$ & $0.00^{*}$ & $27.8 \pm 16.5$ & $0.00^{*}$ \\
\hline PDI & $38.0 \pm 8.5$ & $35.3 \pm 17.8$ & 0.59 & $24.3 \pm 13.7$ & $0.02^{*}$ & $16.1 \pm 15.3$ & $0.00^{*}$ \\
\hline Frequency (Hz) & $1.75 \pm 0.12$ & $1.36 \pm 0.14$ & $0.00^{*}$ & $1.74 \pm 0.18$ & 0.87 & $1.77 \pm 0.12$ & 0.58 \\
\hline Step time (s) & $0.58 \pm 0.04$ & $0.75 \pm 0.08$ & $0.00^{*}$ & $0.58 \pm 0.06$ & 0.90 & $0.57 \pm 0.04$ & 0.39 \\
\hline Irregularity (\%) & $2.48 \pm 1.12$ & $3.42 \pm 1.25$ & 0.08 & $2.36 \pm 0.94$ & 0.71 & $2.24 \pm 0.90$ & 0.24 \\
\hline Step length (m) & $0.62 \pm 0.06$ & $0.54 \pm 0.14$ & $0.048^{*}$ & $0.63 \pm 0.07$ & 0.57 & $0.65 \pm 0.08$ & 0.26 \\
\hline Speed $(\mathrm{m} / \mathrm{s})$ & $1.07 \pm 0.14$ & $0.74 \pm 0.24$ & $0.00^{*}$ & $1.09 \pm 0.14$ & 0.83 & $1.14 \pm 0.16$ & 0.29 \\
\hline Vert. displ. (cm) & $4.34 \pm 0.99$ & $8.73 \pm 2.97$ & $0.00^{*}$ & $4.50 \pm 1.48$ & 0.62 & $4.44 \pm 1.11$ & 0.69 \\
\hline Asymmetry (\%) & $5.61 \pm 4.99$ & $10.71 \pm 6.46$ & $0.04^{*}$ & $5.62 \pm 4.65$ & 0.97 & $6.47 \pm 4.50$ & 0.56 \\
\hline
\end{tabular}

*Significant difference with regard to preoperative $(p<0.05)$; Vert. displ.: vertical displacement of CoM.

however, these differences were not significant. Similar differences between 3 month post-operative patients and healthy subjects were found using height scaled gait parameters (Table 1 )

\subsection{Correlations}

Few, and only weak, correlations (range $r=0.23-0.41$ ) were found between several AGA parameters and clinical outcome scales (KSS, PDI, VAS). The KSS function subscore correlated significantly with every gait parameter except asymmetry, showing correlation coefficients ranging from -0.23 to 0.41 . Womac (sub) score correlated with none of the gait parameters (Table 4).

\section{Discussion}

The current study investigated whether acceleration-based gait analysis (AGA) is suitable for assessing the walking performance of orthopaedic patients. Specifically it evaluated whether AGA is (a) able to differentiate pathological from healthy gait, (b) sensitive to gait changes when monitoring TKA patients during recovery and (c) able to provide additional information beyond the conventional clinical outcome scales.

\subsection{AGA parameters: discriminating patients from healthy participants}

AGA was able to differentiate gait of patients with symptomatic gonarthrosis listed for TKA from healthy gait, showing high sensitivity and specificity. For instance, a threshold level of $60 \mathrm{~cm}$ and lower for the step length showed a sensitivity of $83 \%$ in identifying patients listed for TKA, while only two of the 24 healthy subjects had a step length smaller than $60 \mathrm{~cm}$. The assessment of walking speed showed the best discriminative power in distinguishing pathological from healthy performance achieving an AUC of $89 \%$ (threshold level: $1.11 \mathrm{~m} / \mathrm{s}=4.0 \mathrm{~km} / \mathrm{h}$ ). Actually, AGA is not necessary to determine walking speed, because it can also be measured using a stopwatch. However, for measurements over longer time periods, for instance in daily life conditions, the use of a stopwatch is impractical. In addition AGA produces several gait parameters simultaneously, allowing extended and detailed insight into the function of subjects. These parameters (e.g. step length, frequency) also showed high discriminative power suggesting that combining thresholds for several gait parameters could further improve the discriminative power of AGA. The high sensitivity and specificity values of AGA indicate that accelerometers are powerful tools for identifying deviations in gait shown in patients with symptomatic gonarthrosis listed for TKA. However, even after scaling for body size, there was a range of overlap in gait between the healthy and patient groups, which probably reflects the relatively wide range of different gait styles encountered in the population. Clinical outcome scales assume that healthy subjects score almost excellent results (e.g. KSS between 80 and 100), while worse scores are expected for patients, which assumes that there is no overlap between healthy subjects and patients. However, clinical outcome scales are not primarily intended as a diagnostic tool, but serve mainly to measure outcomes when evaluating patients $[4,6-8,19,20]$. AGA, in contrast, can probably also serve as diagnostic tool. However, further investigation is required into the diagnostic power of AGA in differentiating between pathologies.

Patients listed for TKA showed significantly impaired gait parameters as measured by AGA. The slower walking speed of TKA patients, a combination of significantly lower step frequency and shorter step length, was comparable to previously observed findings using laboratory-based methods [21]. Also the absolute values of the

Table 4

Correlations between AGA parameters and clinical outcome scales.

\begin{tabular}{|c|c|c|c|c|c|c|c|c|}
\hline & & \multicolumn{7}{|c|}{ Clinical outcome scales } \\
\hline & & VAS & KSS knee & KSS function & Womac pain & Womac stiffness & Womac function & PDI \\
\hline \multirow[t]{7}{*}{ GAIT } & Step frequency $(\mathrm{Hz})$ & -0.2 & 0.22 & $-0.34^{*}$ & -0.03 & -0.21 & -0.09 & $-0.29^{*}$ \\
\hline & Step time $(s)$ & 0.21 & -0.22 & $-0.31^{*}$ & 0.02 & 0.17 & 0.09 & $0.30^{*}$ \\
\hline & Irregularity (\%) & 0.11 & -0.14 & $-0.30^{*}$ & 0.07 & 0.19 & 0.09 & $0.26^{*}$ \\
\hline & Step length (m) & -0.16 & -0.13 & $0.30^{*}$ & 0.00 & -0.12 & -0.08 & -0.18 \\
\hline & Walk speed (m/s) & $-0.25^{*}$ & -0.18 & $0.41^{*}$ & -0.02 & -0.2 & -0.1 & $-0.26^{*}$ \\
\hline & Vert. displ. (cm) & $0.24^{*}$ & $-0.39^{*}$ & $-0.34^{*}$ & 0.09 & 0.19 & 0.05 & 0.29 \\
\hline & Asymmetry (\%) & -0.08 & -0.02 & -0.12 & 0.05 & 0.15 & 0.02 & 0.06 \\
\hline
\end{tabular}

Correlation coefficients $\left({ }^{*} p<0.05\right)$; Vert. displ : vertical displacement of CoM. 
gait data produced by AGA were quite similar to other validated methods reported in the literature. For instance, a walking speed of $1.07 \mathrm{~m} / \mathrm{s}$, a step frequency of 1.66 steps/s and a step length of $0.63 \mathrm{~m}$ were found in osteoarthritis patients listed for surgery [2]. These values correspond to the $1.02 \mathrm{~m} / \mathrm{s}, 1.69$ steps/s and $0.60 \mathrm{~m}$ found in the current study.

In this study gait variability was determined by step irregularity and asymmetry. However, variability during gait can be expressed using several definitions, making comparison with other studies impossible. For instance Yakhdani et al. expressed variability as the mean stride-to-stride standard deviation of angular velocity of sagittal knee movements [22], while the current study uses irregularity to express gait variability as the average standard deviation of the left and right step time. Increased irregularity was found in patients indicating that the walk of healthy controls is more regular, while more variation between steps is found in the patient group. This gait pattern may be the result of a compensation strategy for limited function, or it may be due to the instability experienced by these patients [23].

Patients showed higher displacements in a vertical direction than healthy controls. The higher up-down movement in patients while walking may be caused by the symptomatic knee, which is frequently indicated by a limited knee flexion during the stance and swing phase of gait $[13,24,25]$. The increased asymmetry found in pre-operative patients corresponds with previous studies which indicated that patients unload their affected leg as much as possible inducing asymmetric leg behavior [2,26]. In four cases extremely high asymmetry values were obtained (10-18\%). This may be due to the fact that the sample frequency of the accelerometer is too low to accurately identify the peaks which are used to calculate the asymmetry [14]. Because doubts exist about the correctness of these four high asymmetry values, the analysis was also performed without these values. However, no difference in the overall results was found.

\subsection{Post-surgery recovery patterns}

Clinical outcome scales and AGA parameters displayed different post-operative recovery profiles. Immediately after surgery, clinical outcome scales recorded an improvement in function over pre-op levels, while according to the AGA parameters function was reduced. Correspondingly, Harato et al. found a reduction in pain 1 week after TKA, while objective knee function measurements (vertical knee force and knee flexion angle of involved leg) only improved from postoperative day 16-17 [27]. Six weeks following surgery, scores on clinical outcome scales were significantly better than pre-operative, while AGA parameters only reached pre-operative levels. This faster recovery in clinical outcome scales may be due to the subjectivity of the scales which are pain dominated and satisfaction based [6,28]. Pain-free movement, together with the ability to perform a more demanding activity again (e.g. stair climbing) after a certain period of incapacity, results in high patient satisfaction, which is reflected in high scores on clinical outcome scales. This indicates the importance of pain relief for patients shortly following surgery. The considerable changes in gait immediately following intervention, like the significant reduction in walking speed and step length, may be due to adaptations by patients to regain stable and safe gait post-operatively. Such changes in gait are also observed in older subjects compensating for age related impairments in order to regain stability [29].

AGA parameters first started to improve at 6 weeks post-operative, showing improved (not significantly) gait parameters 3 months postoperative compared to pre-operative. The improvements in gait shown during the first 3 months following surgery were similar to the improvements observed in the study by Börjesson et al. who used force plate measurements to analyze the gait of 40 patients suffering knee osteoarthritis. Börjesson's study indicated that the average walking speed increased by $8 \%$ ( 1.07 to $1.16 \mathrm{~m} / \mathrm{s}$ ) from pre-operative to 3 months after surgery, corresponding to the $7 \%(1.07$ to $1.14 \mathrm{~m} / \mathrm{s})$ improvement measured in the current study [2]. The fact that the changes observed were similar in magnitude to those reported by Börjesson [2], but not significant, suggests that the power of the current study is relatively low with respect to these clinically important changes. However, the fact that similar changes were observed shows the applicability of AGA in monitoring patients during recovery.

The clinical outcome scales continued to improve between the 6 weeks and 3 month follow ups. Spencer et al. [30] reported that clinical outcome scores did not change between 3 months and 2 years post-operative. This suggests that clinical outcome scales more or less reach a plateau, which is probably due to fast recovery immediately after surgery. This ceiling effect in clinical outcome scales, when gait has just started to improve, was also indicated by the fact that the KSS knee and function scores improved by $43 \%$ (and $81 \%$ respectively) from pre-operative to 3 months post-operative, suggesting that the KSS ceiling is too low. Step length (and walking speed) improved by $5 \%$ (and 7\%, respectively) from pre-operative to 3 month post-operative, remaining respectively $10 \%$ (and $15 \%$ ) below healthy values.

Three months after surgery, AGA parameters remained significantly below healthy levels. This has previously been shown using laboratory-based methods [13]. Studies indicated that it is mainly the quadriceps strength of the non-affected leg that is involved in improvements in functional performance during the first 3 months, while the relation between functional performance and quadriceps strength of the affected leg increased after 3 months [10]. This suggests that function will improve further beyond 3 months postoperative, and therefore that rehabilitation and physiotherapy may need to continue for longer than 3 months [10,31]. However, longer follow up studies showed that TKA patients even at 1 or 2 years postoperative still walked significantly more slowly than their matched controls [13]. It is also suggested that patients often fail to reach healthy levels, even years after surgery [32]. It is therefore unclear whether the best adapted gait pattern of TKA patients is comparable to healthy levels. Further research is needed to investigate the optimal gait pattern of patients following TKA.

\subsection{Correlations}

In line with previous studies, different recovery profiles were found with AGA and clinical outcome scales, suggesting the usefulness of combining both evaluation methods when evaluating post-operative recovery. Also the lack of, or only weak, correlations observed between the clinical outcome scales and AGA parameters indicate that each assessment measures different aspects of functioning as was previously shown [9,33]. For instance, Hoeymans et al. found low correlations between self-reported disabilities in the activities of daily life and walking speed (range $r=0.13-0.33$ ) [33]. Moderate correlations were found between the Study Short Form Healthy Survey function score and a maximal treadmill walking test $(r=0.43)$ [9]. Also Fuchs et al. showed only weak correlations between locomotion criteria and the Hospital for Special Surgery Score, KSS and VAS score [34]. Most correlations were found between the KSS function subscore and AGA parameters, suggesting that among conventional scores the function score of KSS gives the most objective measure of a patient's functional state. However, this may be due to the fact that questions on the KSS function score are only about walking distance, stair climbing ability and use of a walking aid, which correspond to the AGA-test, while the Womac subscales consist of more varied items about ADL, and the VAS and PDI scales only measure pain [7]. In addition, Womac (sub) scores do not seem to capture objective functional changes as measured by AGA suggesting that Womac (sub) scores lack a functional aspect. Correspondingly, Witvrouw et al. indicated that the outcome of Womac is strongly influenced by factors other than quantitative parameters of the lower extremity, which were measured using an accelerationbased Dynaport Classic Test which consists of the performance of ADL 
activities [5]. The fact that AGA and clinical outcome scales show differences in measuring recovery rates demonstrates the additional value of using AGA for monitoring patients during recovery in clinical practice.

\subsection{Clinical implications}

It has been reported that the new generation of increasingly younger TKA patients are satisfied with the extent of pain relief after surgery, but their expectations about physical function remain unfulfilled [3]. This patient demand for higher post-operative functional levels shows the rising importance of objective assessment of function in clinical practice [3]. To reach optimal functional levels, post-operative rehabilitation programs could be improved by frequent and objective functional assessment. AGA allows the frequent monitoring of patients, providing additional objective information about a patient's function beyond the clinical scales. This suggests the suitability of AGA in providing feedback to the patient, therapist and clinical researcher as part of routine clinical practice. By routinely evaluating the effect of therapy and intervention on recovery, therapy can be adjusted to an individual's needs, which could ultimately optimize the recovery process. However further research is needed to investigate this.

In conclusion, the current study showed the clinical relevance of AGA as a functional assessment tool to identify and routinely monitor patients with symptomatic gonarthrosis in clinical practice.

\section{Conflict of interest statement}

All authors have disclosed any financial and personal relationships with other people or organizations that could inappropriately influence their work.

\section{Acknowledgements}

This study was not sponsored. The study design, the data collection, the analysis and interpretation of data and the writing of the manuscript were done independently.

\section{References}

[1] Ritter MA, Wing JT, Berend ME, Davis KE, Meding JB. The clinical effect of gender on outcome of total knee arthroplasty. J Arthroplasty 2008;23(3):331-6.

[2] Börjesson M, Weidenhielm L, Mattsson E, Olsson E. Gait and clinical measurements in patients with knee osteoarthritis after surgery: a prospective 5-year follow-up study. Knee 2005;12:121-7.

[3] Nilsdotter AK, Toksvig-Larsen S, Roos EM. Knee arthroplasty: Are patients' expectations fulfilled? Acta Orthop 2009;80(1):55-61.

[4] Terwee CB, van der Slikke RMA, van Lummel RC, Benink RJ, Meijers WGH, de Vet HCW. Self-reported physical functioning was more influenced by pain than performance-based physical functioning in knee-osteoarthritis patients. J Clin Epidemiol 2006;59:724-31.

[5] Witvrouw E, Victor J, Bellemans J, Rock B, Van Lummel R, van der Slikke R. A correlation study of objective functionality and WOMAC in total knee arthroplasty. Knee Surg Sports Traumatol Arthrosc 2002;10(6):347-51.

[6] Liebensteiner MC, Herten A, MGstoettner AH, Thaler M, Krismer M, Back CM Correlation between objective gait parameters and subjective score measurements before and after total knee arthroplasty. Knee 2008;15:461-6.
[7] Lingard EA, Katz JN, Wright RJ, Wright EA, Sledge CB, The Kinemax Outcomes Groups. Validity and responsiveness of the knee society clinical rating system in comparison with the SF-36 and WOMAC. J Bone Joint Surg 2001;83-A(12):1856-64.

[8] Stratford PW, Kennedy DM. Does parallel item content on WOMAC's pain and function subscales limit its ability to detect change in functional state? BMC Musculoskelet Disord 2004;5:17-25.

[9] Wittink H, Rogers W, Sukiennik A, Carr DB. Physical functioning: self-report and performance measures are related but distinct. Spine 2003;28:2407-13.

[10] Yoshida Y, Mizner RL, Ramsey DK, Snyder-Mackler L. Examining outcomes from total knee artrhoplasty and the relationship between quadriceps strength and knee function over time. Clin Biomech 2008;23(3):320-8.

[11] Ishii Y, Terajima K, Koga Y, Takahashi HE, Bechtold JE, Gustilo R. Gait analysis after total knee arthroplasty. Comparison of posterior cruciate retention and substitution. J Orthop Sci 1998;3(6):310-7.

[12] Saleh M, Murdoch G. In defence of gait analysis. Observation and measurement in gait assessment. J Bone Joint Surg 1985;67-B(2):237-40.

[13] Benedetti MG, Catani F, Bilotta TW, Marcacci M, Mariani E, Giannini S. Muscle activation pattern and gait biomechanics after total knee replacement. Clin Biomech 2003;28(9):871-6.

[14] Senden R, Grimm B, Heyligers IC, Savelberg HHCM, Meijer K. An accelerationbased gait test for healthy subjects: Reliability and reference data. Gait Posture 2009;30(2):192-6.

[15] Grimm B, Vanderherst T, Munch C. Heyligers I.C. Application feasibility of accelerometer based gait analysis in clinical orthopaedics. J Biomech 2006;39: S110.

[16] Brandes M, Zijlstra W, Heikens S, Lummel van R. Accelerometry based assessment of gait parameters in children. Gait Posture 2006;24:482-6.

[17] Zijlstra W, Hof AL. Assessment of spatio-temporal gait parameters from trunk accelerations during human walking. Gait Posture 2003;18:1-20.

[18] Hof AL. Scaling gait data to body size. Gait Posture 1996;4:222-3.

[19] Insall J. Rating systems for total knee replacement. Knee 2002;9(4):261-6.

[20] Kreibich DN, Vaz M, Bourne RB, Rorabeck CH, Kim P, Hardie R, et al. What is the best way of assessing outcome after total knee replacement? Clin Orthop Relat Res 1996;331:221-5.

[21] Ivarsson I, Gillquist J. Rehabilitation after high tibial osteotomy and unicompartmental arthroplasty. A comparative study. Clin Orthop 1991;266:139-44.

[22] Yakhdani HRF, Bafghi HA, Meijer OG, Bruijn SM, Dikk van den N, Stibbe AB, et al. Stability and variability of knee kinematics during gait in knee osteoarthritis before and after replacement surgery. Clin Biomech 2010;25(3):230-6.

[23] Fitzgerald GK, Piva SR, Irrgang JJ. Reports of joint instability in knee osteoarthritis: its prevelance and relationship to physical function. Arthritis Rheum 2004;51: 941-6.

[24] Finch E, Walch M, Thomas SG, Woodhouse LJ. Functional ability perceived by individuals following total knee arthroplasty compared to age-matched individuals without knee disability. J Orthop Sports Phys Ther 1998;27(4):255-63.

[25] Milner CE. Is gait normal after total knee arthroplasty? Systematic review of the literature. J Orthop Sci 2009;14(1):114-20.

[26] Mizner RL, Snyder-Mackler L. Altered loading during walking and sit-to-stand is affected by quadriceps weakness after total knee arthroplasty. J Orthop Res 2005;23:1083-90.

[27] Harato K, Otani T, Nakayama N, Watarai H, Wada M, Yoshimine F. When does post-operative standing function after total knee arthroplasty improve beyond pre-operative level of function? Knee 2009;16:112-25.

[28] Mandeville D, Osternig LR, Chou LS. The effect of total knee replacement surgery on gait stability. Gait Posture 2008;27(1):103-9.

[29] Winter DA, Patla AE, Frank JS, Walt SE. Biomechanical walking pattern changes in the fit and healthy elderly. Phys Ther 1990;79(6):340-7.

[30] Spencer JM, Chauhan SK, Sloan K, Taylor A, Beaver RJ. Computer navigation versus conventional total knee replacement. No difference in functional results at two years. J Bone Joint Surg Br 2007;89B(4):477-80.

[31] Webster KE, Wiitwer JE, Feller JA. Quantitative gait analysis after medial unicompartmental knee arthroplasty for osteoarthritis. J Arthroplasty 2003;18(6): 751-9.

[32] Lee TH, Tsuchida T, Kitahara H, Moriya H. Gait analysis before and after unilateral total knee arthroplasty. Study using a linear regression model of normal controlswomen without arthroplasty. J Orthop Sci 1999;4:13-21.

[33] Hoeymans N, Feskens EJ, van den Bos GA, Kromhou D. Measuring functional status: cross sectional and longitudinal associations between performance and self-report. J Clin Epidemiol 1996;49:1103-10.

[34] Fuchs S, Genkinger M, Laass H, Rosenbaum D. Results of bicondylar sledge prostheses with special reference to gait pattern. Biomed Tech (Berl) 2001;46: 142-6. 